\title{
Multi Ultrasonic Electronic Travel Aids (MU-ETA) Sebagai Alat Bantu Penunjuk Jalan Bagi Tuna Netra
}

\author{
Mujtahid Aktanto \\ ${ }^{1 .}$ Prodi S2 Teknobiomedik, Sekolah Pascasarjana Universitas Airlangga, Surabaya \\ e-mail: *11Mujtahid84@yahoo.com
}

\begin{abstract}
Abstrak
Tujuan dari penulisan jurnal ini adalah untuk mendesain sebuah instrument berupa Electronic Travel Aids (ETA) yang dapat mendeteksi halangan pada 3 bagian tubuh sekaligus yaitu bagian kepala, dada dan kaki. ETA ini berbasis Mikrokontroler ATMEGA32 dan menggunakan sensor ultrasonik HC-SR04. Multi Ultrasonik Electronic Tavel Aids ini digunakan sebagai alat pemandu bagi penderita tuna netra. Dalam mengukur ketepatan jarak baca terhadap halangan, kalibrasi dari sensor ultrasonik HC-SRO4 sangat diperlukan. Data yang telah di uji dari masing-masing sensor dihitung untuk mendapat hasil error rate dan standart deviasi. Dan terakhir, data-data tersebut diolah pada stastistik dan dihitung dengan kalkulasi menggunakan metode uji T-Test berpasangan agar mendapatkan hasil sesuai dengan jarak yang ada.

Sesuai dengan hasil dari penelitian ini menunjukan bahwa sensor HC-SR04 dapat diteima sebagai pengganti alat pengukuran jarak dikarenakan hasil pembacaan Error Rate dan standart deviasi.pada alat. Setelah sensor ultrasonic dapat diterima sebagai alat untuk mengukur jarak, baru dibuat logika output berdasarkan sensor yang ada agar dapat mengenali benda yang ada di depan.
\end{abstract}

Kata kunci-3-5 mikrokontroler, ATMEGA32, Ultrasonik Sensor, Tuna Netra, Visually

Impaired, Electronic Tavel Aids(ETA) Halangan/Obstacle

Abstract

The Objective of this study is to develop an ETA instrument which able to detecting obstacle in Head, Chest dan Leg areas at the same time. This ETA based on Microcontroller ATMEGA32 and HC-SRO4 Ultrasonic Sensor. This Multi Ultrasonic Electronic Travel Aids is used as guide device for visually impaired person. to measure the distance of the obstacles, calibration the ultrasonic sensor are needed. the data tested from each ultrasonic sensor calculated to get error rate and standart deviation. And finally, the data were analyzed based on statistic using Paired T-Test method to accept the sensore as a distance measure device.

The result of the study showed that HC-SRO4 are accepted as the replacement of distance measure device because of error rate result are less than 3\%. and MU ETA can handle the obstacle well in passing the obstacle test on Head, Chest and leg area

Keyword : Microcontroller, ATMEGA32, Ultrasonic Sensor, Tuna Netra, Visually Impaired, Electronic Traver Aids (ETA), Obstacle

JBP Vol. 18, No. 2, Agustus 2016-Mujtahid Aktanto 


\section{PENDAHULUAN \\ 1.1 Latar belakang}

Indera penglihatan adalah salah satu sumber informasi yang vital bagi manusia. Jumlah informasi yang diterima manusia dari lingkungan adalah $1 \%$ dari rasa, $1,5 \%$ dari kulit, 3,5\% dari bau, $11 \%$ dari pendengaran, dan 83\% dari penglihatan (Shruti, 2011). Hal inilah yang menyebabkan indera penglihatan dianggap sebagai salah satu indera paling penting bagi manusia. Tidak berlebihan apabila dikemukakan bahwa sebagian besar informasi yang diperoleh oleh manusia berasal dari indera penglihatan, sedangkan selebihnya berasal dari panca indera yang lain. Mata merupakan indera penglihatan yang berfungsi sebagai perekam keadaan/kondisi disekitar yang kemudian sinyal hasil rekaman ini diolah oleh otak, sehingga manusia bisa mengerti tentang apa yang dilihatnya. Sebagai konsekuensinya, bila seseorang mengalami gangguan pada indera penglihatan, maka kemampuam aktifitas akan sangat terbatas, karena informasi yang diperoleh akan jauh berkurang dibandingkan mereka yang berpenglihatan normal.

Data gangguan penglihatan di seluruh dunia diperoleh dari hasil estimasi yang dilakukan oleh WHO. Klasifikasi gangguan penglihatan yang digunakan adalah berdasarkan tajam tidaknya penglihatan. Low vision jika tajam penglihatan berkisar $<6 / 18$ $\geq 3 / 60$ dan buta jika tajam penglihatan kurang dari 3/60 dalam satuan ukuran tingkat kebutaan mata (Global Data on Visual Impairment 2010, WHO 2012). Estimasi jumlah orang dengan gangguan penglihatan di seluruh dunia pada tahun 2010 adalah 285 juta orang atau $4,24 \%$ populasi, sebesar $0,58 \%$ atau 39 juta orang menderita kebutaan dan $3,65 \%$ atau 246 juta orang mengalami low vision (Global Data on Visual Impairment 2010, WHO 2012). Data nasional mengenai besaran masalah gangguan indera penglihatan pernah dikumpulkan melalui berbagai survei, antara lain Survei Kesehatan Mata, Survei Kesehatan Nasional/Survei Kesehatan Rumah Tangga, Riset Kesehatan Dasar dan Rapid Assessment of Avoidable Blindness (RAAB). Riset Kesehatan Dasar (Riskesdas) 2007 dan
2013 mengumpulkan data mengenai kesehatan indera penglihatan, yaitu prevalensi kebutaan pada usia 55-64 tahun sebesar 1,1\%, usia 6574 tahun sebesar 3,5\% dan usia 75 tahun ke atas sebesar 8,4\%. Meskipun pada semua kelompok umur sepertinya prevalensi kebutaan di Indonesia tidak tinggi, namun di usia lanjut masih jauh di atas $0,5 \%$ yang berarti masih menjadi masalah kesehatan masyarakat (Riskesdas 2013 Kementrian Kesehatan, 2013). Hasil Riskesdas 2013 juga mendapatkan prevalensi kebutaan pada perempuan lebih tinggi. Prevalensi kebutaan pada laki-laki adalah 0,3\% sedangkan pada perempuan 0,5\% (Riskesdas 2013 Kementrian Kesehatan, 2013).

Pada umumnya penyandang tuna netra menggunakan tongkat untuk mengetahui jarak yang ada disekitarnya. Tongkat biasanya digunakan jika berjalan di luar ruangan. Tetapi jika di dalam ruangan, tongkat tidak dipakai karena takut merusak barang-barang pecah belah. Kekurangan lain dari tongkat yaitu biasanya hanya untuk meraba benda benda/ halangan yang berada di bawah, dan halangan seperti mobil/truk sering tidak terdeteksi oleh tongkat. Penyandang tuna netra juga mengalami kendala untuk menentukan jarak obyek yang ada disekitarnya, misalnya teman yang diajak bicara, dll. Dengan kemajuan di bidang teknologi maka telah dikembangkan suatu alat yang dinamakan Electronic Travel Aids (ETA), merupakan alat bantu mobilitas untuk tuna netra berbasis elektronik. ETA pada umumnya menggunakan gelombang ultrasonik untuk mendeteksi keberadaan suatu objek. Gelombang ultrasonik ini akan dipancarkan dan sinyal yang mengenai suatu objek sebagian akan dipantulkan kembali. Sinyal pantul akan diterima oleh suatu penerima untuk kemudian diolah menjadi sebuah informasi. Beberapa ETA yang sudah tersedia masih belum dapat diterima sepenuhnya oleh masyarakat tunanetra karena kompleksitas fitur yang disempurnakan dan biaya tinggi. Dasar dari setiap perangkat bantu adalah kegunaan, portabilitas, keamanan dan kecekatan. Fakta yang paling penting adalah bahwa alat yang didesain itu harus terjangkau oleh pengguna. 
Dalam beberapa tahun terakhir beberapa ETA telah dikembangkan untuk membantu tunanetra dalam navigasi keselamatan yang berbasis ultrasonik. Ini termasuk beberapa peneltian yang telah dilakukan antara lain : Ultrasonic Spectacles and Waist-belt (Bhatlawande, 2012) merupakan salah satu ETA yang terdiri 2 bagian yaitu sabuk yang memiliki 3 sensor ultrasonik dan kacamata yang memiliki 2 sensor ultrasonik. Alat ini memiliki keunggulan yaitu keakuratan deteksi benda yang berada di sebelah kanan dan kiri serta benda yang berada didepan bagian pinggang hingga ke kepala. Namun memiliki kelemahan dalam mendeteksi benda yang letaknya di bagian depan bawah pinggang hingga ke kaki.

Penelitian lainnya yaitu Embeded Glove (Sankaar et all, 2013). Embedded Glove merupakan ETA yang berupa sarung tangan yang memiliki 3 sensor ultrasonik sekaligus. Alat ini memiliki kelebihan yaitu penggunaan yang mudah berupa sarung tangan serta waktu respon yang lebih cepat dari ETA berbasis ultrasonik lainnya. Namun Embedded Glove ini memiliki kekurangan yaitu hanya bisa merespon keberadaan benda di satu sudut dalam satu waktu dan kurangnya keakuratan pembacaan sensor karena posisi tangan selalu berubah-ubah.

Penelitian a wearable multipoint ultrasonic travel aids (Ercoli et all, 2013). Penelitian ini menciptakan ETA berbasis ultrasonik yang terdiri 4 sensor ultrasonik yang diletakkan pada perut pengguna dan membentuk sudut tertentu sehingga bisa mendeteksi object yang berada di depan, kanan, kiri, dan bawah. Kelebihan dari alat ini adalah respon time yang cepat dan pemakaian yang mudah. Sedangkan kekurangan alat ini adalah tidak bisa mendeteksi benda yang berada di bagian dada hingga kepala.

Penelitian terbaru yaitu Virtual Eye for the Blind (Pooja et all, 2015). Penelitian ini mendesain ETA yang tediri dari 4 sensor ultrasonik yang diletakkan pada topi, lengan kanan dan lengan kiri, dan belakang. Kelebihan yang dimiliki ETA ini adalah memiliki GPS dan SDcard untuk penyimpanan data GPS serta bisa mendeteksi object yang berada dibelakang. Kekurangan dari ETA ini adalah respon time yang lebih lama dibanding ETA lainnya dan tidak bisa mendeteksi object yang berada depan bawah pengguna.

Dari beberapa penelitian ETA yang telah dilakukan sebelumnya selalu ada kelemahan pada batasan wilayah sensor pendeteksi objek, yaitu belum ada ETA yang memiliki fitur pengenalan objek untuk mengenali benda yang berada didepan kaki dan kepala secara bersamaan. Sebagai pengembangan ETA pada penelitian ini, ETA berbasis sensor ultrasonik yang didesain adalah Multi Ultrasonic Electronic Travel Aids yang terdiri 2 sensor pada jaket, 2 sensor pada kacamata, dan 1 sensor pada lutut, userfriendly, biaya yang ekonomis, lengkap serta berdaya konsumsi listrik rendah. Multi Ultrasonic Electronic Travel Aids berfungsi sebagai penunjuk jalan bagi tuna netra. Alat tersebut ini mampu memberikan cakupan area yang lebih baik untuk mendeteksi rintangan dan terjangkau. Multi Ultrasonic Electronic Travel Aids (ETA), yang didesain memiliki kelebihan agar tuna netra dapat melintasi ruangan serta luar lingkungan dengan keyakinan yang sama dengan orang berpenglihatan normal. Alat ini mendeteksi rintangan dan member peringatan pengguna, sementara keputusan untuk bergerak ke arah yang benar dibuat hanya oleh pengguna yang memakai alat ini. Obstacle detection dimungkinkan hingga berjarak sekitar $3 \mathrm{~m}$.

\subsection{Rumusan masalah}

1. Bagaimana merancang Multi ETA berbasis ultrasonik yang mampu mendeteksi halangan di depan bagian kepala, dada, dan kaki dalam waktu yang bersamaan?

2. Bagaimanakah mendesain Multi ETA yang dapat digunakan sebagai penunjuk jalan bagi tuna netra sesuai dengan karakteristik mikrokontroller dan sensor yang dipergunakan?

\subsection{Tujuan penelitian}


adalah,

Adapun tujuan pada penelitian ini

1. Mendesain Multi ETA berbasis sensor ultrasonik yang mampu mendeteksi halangan pada bagian kepala, dada dan kaki secara bersamaan dengan cara mengatur perintah logika pada mikrokontroller dan juga pada masing-masing sensor ultrasonik.

2. Mendesain Multi ETA sesuai dengan Karakteristik sensor ultrasonik dan mikrokontroler dengan cara kalibrasi pengukuran jarak sensor, melakukan inisialisasi Port pada IC ATMEGA32, Membuat logika Output dari ETA agar dapat di pergunakan menjadi alat penunjuk jalan bagi tuna netra.

\subsection{Manfaat penelitian}

1. Manfaat teori

Dengan adanya penelitian ini diharapkan mampu memberikan suatu informasi ilmiah mengenai metode pengembangan instrumentasi elektronika ke dalam dunia medis serta harus mampu memberikan manfaat atau guna dari terhadap penderita tuna netra.

2. Manfaat praktis

Membuat desain ETA yang diharapkan dapat membantu menyelesaikan masalah bagi penyandang tuna netra dalam mengenali lingkungan sekitarnya dan berjalan sesuai arah yang diinginkan seiring berjalannya kemajuan teknologi.

\subsection{Batasan Masalah}

Pembahasan dibatasi beberapa hal sebagai berikut :

1. Multi ETA menggunakan mikrokontroller IC ATMEGA32 sebagai minimum system alat.

2. Multi ETA Menggunakan inputan Sensor Ultrasonik HC-SR04 buatan china.

3. Multi ETA menggunan LCD $2 \times 16$ 4Bit Hitachi, Buzzer local 3,5V serta Motor DC 3,7V.
4. Pengujian dilakukan dengan jarak 3 $\mathrm{cm}-3$ Meter.

5. pengujian dilakukan indoor dengan objek yang telah ditentukan (kardus).

\section{TINJAUAN PUSTAKA}

\subsection{Mata}

Salah satu alat optik alamiah yang merupakan anugerah dari Sang Pencipta adalah mata. Indera penglihatan terdiri dari 3 komponen utama yaitu mata yang memfokuskan bayangan dari luar ke retina, sistem syaraf yang menyalurkan informasi ke otak, dan korteks penglihatan sebagai tempat pengolah informasi. Mata pada manusia adalah vision sensor yang bertugas menangkap gejala-gejala pada lingkungan untuk diolah dan diambil informasi yang ada.

Menurut Utami, Meskipun sama-sama berfungsi sebagai vision sensor, mata memiliki kelebihan yang jauh lebih baik dari kamera biasa (Utami,2010). Kelebihan tersebut diantara lain:

a. Mata dapat mengamati objek dengan sudut yang sangat besar.

b. Sudah terdapat kelopak mata dan cairan lubrikasi yang bekerja sebagai sistem pembersih pada mata.

c. Mata memiliki autofocus yang memungkinkan kita melihat benda dengan jarak $20 \mathrm{~cm}$ dalam satu detik.

d. Mata dapat bekerja menerima cahaya dengan rentang intensitas yang sangat lebar.

e. Mata memiliki sistem penyesuaian bukaan lensa yang otomatis.

f. Kornea pada mata memiliki sistem penghapus goresan yang siap pakai.

g. Mata memiliki sistem pengendali tekanan otomatis yang dapat mempertahankan tekanan internalnya sekitar $1,6 \mathrm{kPa}$ sehingga bentuk bola mata dapat dipertahankan.

\subsection{Personal Space}

\subsubsection{Pengertian Personal Space}

Istilah personal space pertama kali digunakan oleh Katz pada tahun 1973 dan bukan merupakan sesuatu yang unik dalam istilah psikologi, karena istilah ini 
juga dipakai dalam bidang biologi, antropologi, dan arsitektur (Yusuf, 1991).

Selanjutnya dikatakan bahwa studi personal space merupakan tinjauan terhadap perilaku hewan dengan cara mengamati perilaku mereka berkelahi, terbang, dan jarak social antara yang satu dengan yang lain. Kajian ini kemudian ditransformasikan dengan cara membentuk pembatas serta dapat pula diumpamakan semacam gelembung yang mengelilingi individu dengan individu yang lain.

\subsubsection{Zona Interaksi Sosial}

Menurut Edward T. Hall (1976) seorang antropolog, bahwa dalam interaksi social terdapat empat zona spasial yang disebut Zona Interaksi Sosial meliputi : jarak intim, jarak personal, jarak social, dan jarak public.

1. Jarak Intim

a. Jarak yang dekat/akrab atau keakraban dengan jarak $45 \mathrm{Cm}$.

b. Pada jarak 15, kontak fisik merupakan hal yang penting

c. Jarak yang diperuntukkan pada "intimate lovers"

d. Menyenangkan ketika berinteraksi dengan orang lain yang dicintai, tidak menyenangkan dalam situasi yang lain.

2. Jarak Pribadi

a. Karakteristik keregangan yang biasa dipakai individu satu sama lain.

b. Jarak antara $45 \mathrm{~cm}-1.3 \mathrm{M}$

c. Fase dekat $(45 \mathrm{~cm}-75 \mathrm{~cm})$ dan fase jauh $(75 \mathrm{~cm}-1.2 \mathrm{M})$.

d.Fase dekat : masih memungkinkan pertukaran sentuhan, bau, pandangan, dan isyarat - isyarat lainnya.

e. Fase jauh : jarak dimana masing masing orang dapat saling menyentuh dengan mengulurkan tangan. Komunikasi halus (fine grain communication) masih dapat diamati.

f. Transisi antara kontak intim dengan tingkah laku umum yang agak formal.
3. Jarak Sosial

a. Jarak $1,2 \mathrm{M}-3.6 \mathrm{M}$

b. Jarak yang memungkinkan terjadinya kontak social yang umum, seperti hubungan bisnis.

c. Fase dekat $(1,2 \mathrm{M}-2.1 \mathrm{M})$

d. Fase jauh $(2.1 \mathrm{M}-3,6 \mathrm{M})$

4. Zona Publik

a. Jarak 3,6 M-7,6 M

b. Isyarat - isyarat komunikasi sedikit

c. Situasi formal atau pembicaraan umum / orang - orang yang berstatus lebih tinggi.

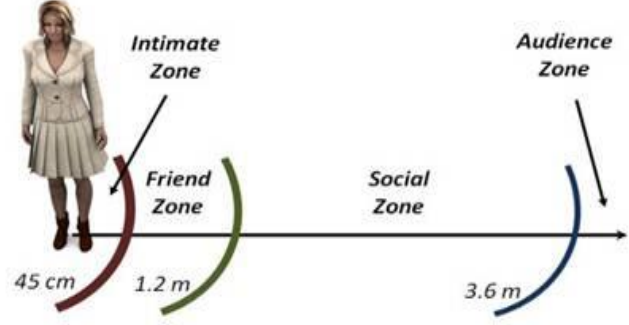

Personal Space

Gambar 2.2 Jarak Personal Space (Hall,1976)

\subsection{Electronic Travel Aids (ETA)}

Electronic Travel Aids atau ETA memiliki fungsi yang sama dengan alat bantu tradisional lainnya yaitu untuk membantu para penderita kebutaan dalam mendapatkan informasi dari lingkungannya agar mereka bisa mencapai tempat tujuan. Secara khusus ETA dibuat untuk memenuhi kebutuhan akan mobilitas dan komunikasi bagi penderita kebutaan. ETA memiliki daya jangkau yang lebih luas dibanding dengan tongkat tradisional. Tongkat tradisional hanya memiliki jarak jangkau sepanjang maksimal tongkat sedangkan ETA yang ada selama ini sendiri memiliki jarak jangkau minimal 3 meter. Prinsip pengenalan objek pada ETA sendiri secara umum adalah dengan mengukur jarak. ETA akan mengetahui berapa jarak benda yang ada di depan pengguna dan memberikan peringatan jika jarak itu sudah masuk pada batas yang telah ditentukan.

Secara umum, terdapat 3 unsur utama dalam ETA yaitu sensor, processing unit, dan output. 
Sensor disini berguna untuk mengambil informasi tentang lingkungan lalu di olah oleh processing dan output adalah sistem peringatan yang digunakan sebagai pengingat jika terdapat halangan di depan penderita.

Sudah banyak ETA yang dibuat berdasarkan metode pengukuran jarak seperti yang telah dijelaskan di atas. Berikut beberapa contoh ETA yang telah di kembangkan sampai saat ini disajikan pada Tabel 2.1.

Tabel 2.1 Multi ETA dengan ultrasound sensor (Mithal, 2010)
\begin{tabular}{|l|l|l|}
\hline No & ETA Ultrasound sensor & Spesifikasi \\
\hline 1. & Nottingham Detector & $\begin{array}{l}\text { a. Pendeteksi halangan berupa } \\
\text { sensor ultrasound } \\
\text { b. alat mudah dibawa-kemana } \\
\text { c. menggunakan 8 buah sensor } \\
\text { dengan frekuensi 40kHz } \\
\text { d. daya jangkauan maksimum 2,1 } \\
\text { 2. Meter }\end{array}$ \\
\hline 3. & Lindsay Russell Path & $\begin{array}{l}\text { a. pendeteksi halanan berupa } \\
\text { sensor ultrasound }\end{array}$ \\
& Sonic Guide & $\begin{array}{l}\text { b. daya jangkau maksimum 1,8 } \\
\text { c. ETA diletakkan di leher } \\
\text { d. output berupa getaran dan alarm }\end{array}$ \\
\hline & $\begin{array}{l}\text { a. ETA dipasang di kepala } \\
\text { b. pendeteksi halangan berupa }\end{array}$ \\
& $\begin{array}{l}\text { c. daya jangkau maksimum } 6 \text { meter } \\
\text { d. output berupa alarm dan getaran }\end{array}$ \\
\hline
\end{tabular}

\subsubsection{Sensor Jarak Ultrasonik}

Gelombang ultrasonik adalah gelombang mekanik yang mempunyai daerah frekuensi diatas kemampuan manusia atau diatas 20 Khz. Karena frekuensinya yang tinggi, gelombang ini lebih mudah diarahkan dari pada gelombang yang berada di bawah daerah frekuensinya. Gelombang ini biasa digunakan dalam aplikasi pengukuran jarak. Berdasarkan datasheet (Jameco Electonic,2008), modul ini dapat digunakan untuk mengukur jarak benda sejauh $3 \mathrm{~cm}$ sampai $300 \mathrm{~cm}$. Sistem ini dapat diterapkan pada $M U$-ETA sebagai pengindra adanya halangan.

Sensor jarak ultrasonik HC-SR04 adalah sensor $40 \mathrm{KHz}$ produksi parallax yang umum digunakan untuk aplikasi atau kontes robot cerdas untuk mendeteksi jarak suatu objek.

Sensor HC-SR04 mendeteksi jarak objek dengan cara memancarkan gelombang ultrasonik $(40 \mathrm{KHz})$ selama $\mathrm{t}=\min 10 \mathrm{us}$ kemudian mendeteksi pantulannya. Sensor HC-SR04 memancarkan gelombang ultrasonik sesuai dengan kontrol dari mikrokontroller pengendali (pulsa trigger dengan $t_{\text {Out }} \min 10$ $\mu \mathrm{s})$. Spesifikasi sensor ini menurut datasheet sensor (electfreaks, 2011),

a. Kisaran pengukuran $2 \mathrm{~cm}-4$ Meter.

b. Input trigger-positive TTL pulse, $10 \mu \mathrm{S}$ min. pulse.

c. Echo hold off $50 \mathrm{uS}$ from fall of trigger

d. Delay before next measurement $60 \mathrm{mS}$. HC-SR04 ULTRASONIC MODULE

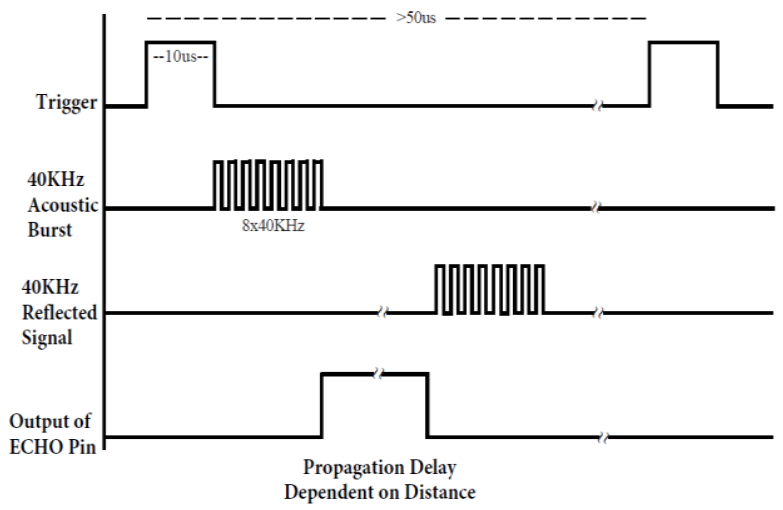

Gambar 2.5 Diagram waktu sensor HC-SR04 (Electfreaks,2011)

\subsubsection{Prinsip Kerja Sensor}

Pada dasanya, Sensor HC-SR04 terdiri dari sebuah chip pembangkit sinyal $40 \mathrm{KHz}$, sebuah speaker ultrasonik dan sebuah mikropon ultrasonik. Speaker ultrasonik mengubah sinyal $40 \mathrm{KHz}$ menjadi suara sementara mikropon ultrasonik berfungsi untuk mendeteksi pantulan suaranya (Electfreaks,2011). Sensor HC-SR04 mendeteksi jarak obyek dengan cara memancarkan gelombang ultrasonik $(40 \mathrm{kHz})$ selama $\mathrm{t}_{\text {BURST }}(10 \mu \mathrm{s})$ kemudian mendeteksi pantulannya. Sensor PING memancarkan gelombang ultrasonik sesuai dengan kontrol dari mikrokontroler pengendali (pulsa trigger dengan $\left.\mathrm{t}_{\text {out }} \min .10 \mu \mathrm{s}\right)$.

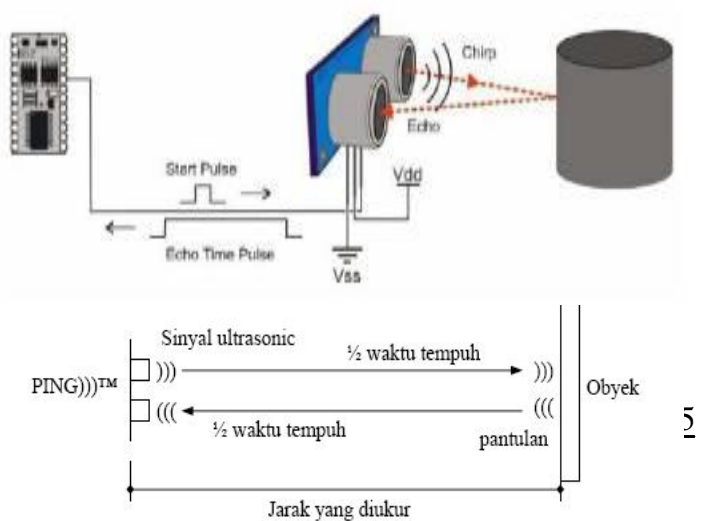

Jarak yang diukur

JBP Vol. 18, No. 2, Agustus 2016-Mujtahid Aktanto 
Jurnal Biosains Pascasarjana Vol. 18 (2016) pp

(C) (2016) Sekolah Pascasarjana Universitas Airlangga, Indonesia

Gambar 2.6 Prinsip kerja sensor Ultrasonik (Jameco Electronic,2008)

Gelombang ultrasonik ini melalui udara dengan kecepatan 344 meter per detik, mengenai obyek dan memantul kembali ke sensor. HC-SR04 mengeluarkan pulsa output high pada pin Trigger setelah memancarkan gelombang ultrasonik dan setelah gelombang pantulan terdeteksi pin Echo akan membuat output high pada pin Echo. Lebar pulsa High $\left(\mathrm{t}_{\text {in }}\right)$ akan sesuai dengan lama waktu tempuh gelombang ultrasonik untuk $2 \mathrm{x}$ jarak ukur dengan obyek (Electfreaks, 2009). Maka jarak yang diukur adalah

$\mathrm{S}=\left(\mathrm{t}_{\text {in }} \times \mathrm{V}\right) / 2$

Dimana :

$\mathrm{S}=$ Jarak antara sensor ultrasonik dengan

objek yang dideteksi

$\mathrm{V}=$ Cepat rambat gelombang ultrasonik di

udara $(344 \mathrm{~m} / \mathrm{s})$

$\mathrm{t}_{\mathrm{in}}=$ Selisih waktu pemancaran dan

penerimaan pantulan gelombang.

Sensor berfungsi untuk menyediakan informasi umpan balik untuk mengendalikan program dengan cara mendeteksi keluaran. Sensor itu sendiri terdiri dari tranduser dengan atau tanpa penguat atau pengolah sinyal yang terbentuk dalam satu sistem pengindera. Dalam lingkungan sistem pengendali dan robotika, sensor memberikan kesamaan yang menyerupai mata, pendengaran, hidung, lidah yang kemudian akan diolah oleh kontroler sebagai otaknya. Sensor dibedakan menjadi dua, yakni sensor pasif dan sensor aktif. Sensor pasif adalah sensor yang dalam sistem kerjanya tidak dapat menghasilkan tegangan sendiri tetapi dapat menghasilkan perubahan nilai resistansi, kapasitansi, dan induktansi pada lingkungan sekelilingnya. Perubahan ini menyebabkan perubahan tegangan atau arus yang dihasilkan tranduser. Perubahan inilah yang dimanfaatkan untuk mengetahui keadaan yang diukur.

\subsection{Mikrokontoller}

Mikrokontroler adalah sebuah sistem komputer lengkap dalam satu serpih (chip). Dalam datasheet-nya, Mikrokontroler lebih dari sekedar sebuah mikroprosesor karena sudah terdapat atau berisikan ROM (ReadOnly Memory), RAM (Read-Write Memory), beberapa bandar masukan maupun keluaran, dan beberapa peripheral seperti pencacah/pewaktu, ADC (Analog to Digital converter), DAC (Digital to Analog converter) dan serial komunikasi. Salah satu mikrokontroler yang banyak digunakan saat ini yaitu mikrokontroler AVR. AVR adalah mikrokontroler RISC (Reduce Instuction Set Computer) 8 bit berdasarkan arsitektur Harvard. Secara umum mikrokontroler AVR dapat dapat dikelompokkan menjadi 3 kelompok, yaitu keluarga AT90Sxx, ATMega dan ATtiny. Pada dasarnya yang membedakan masing-masing kelas adalah memori, peripheral, dan fiturnya Seperti mikroprosesor pada umumnya, secara internal mikrokontroler ATMega16 terdiri atas unit-unit fungsionalnya Arithmetic and Logical Unit (ALU), himpunan register kerja, register dan dekoder instruksi, dan pewaktu beserta komponen kendali lainnya. Berbeda dengan mikroprosesor, mikrokontroler menyediakan memori dalam serpih yang sama dengan prosesornya (in chip) (Atmel Coporation, 2003).

\subsubsection{Arsitektur ATMEGA32}

Mikrokontroler ini menggunakan arsitektur Harvard yang memisahkan memori program dari memori data, baik bus alamat maupun bus data, sehingga pengaksesan program dan data dapat dilakukan secara bersamaan (concurrent). Secara garis besar mikrokontroler ATMega32 terdiri dari :

1. Arsitektur RISC dengan throughput mencapai 16 MIPS pada frekuensi 16Mhz.

2. Memiliki kapasitas Flash memori 32Kbyte, EEPROM 1024 Byte, dan

SRAM 2Kbyte

3. Saluran I/O 32 buah, yaitu Bandar A, Bandar B, Bandar C, dan Bandar D.

4. CPU yang terdiri dari 32 buah register.

5. User interupsi internal dan eksternal

5. Bandar antarmuka SPI dan Bandar USART sebagai komunikasi serial

6. Fitur Peripheral 
a. Dua buah 8-bit timer/counter dengan prescaler terpisah dan mode compare

b. Satu buah 16-bit timer/counter dengan prescaler terpisah, mode compare, dan mode capture

c. Real time counter dengan osilator tersendiri

d. Empat kanal PWM dan Antarmuka komparator analog

e. 8 kanal, 10 bit ADC

f. Byte-oriented Two-wire Serial Interface

g. Watchdog timer dengan osilator internal

\subsubsection{Konfigurasi Pena (Pin) ATMEGA32}

Konfigurasi pena (pin) mikrokontroler Atmega32 dengan kemasan 40-pena dapat dilihat pada Gambar 2.8. Dari gambar tersebut dapat terlihat ATMega16 memiliki 8 pena untuk masing-masing bandar A (Port A), bandar B (Port B), bandar C (Port C), dan bandar D (Port D).

\subsection{Bahasa Pemrograman $C$ 2.5.1 Bahasa C}

Bahasa BCPL yang dikerjakan oleh Martin Richards pada tahun 1967 merupakan awal dari lahirnya bahasa C. Ken Thompson memulai pengembangan bahasa BCPL yaitu bahasa B pada tahun 1970. Perkembangan selanjutnya dari bahasa B dikembangkan menjadi bahasa $\mathrm{C}$ oleh Dennis Ritchie beberapa bulan berikutnya di Bell Telephone Laboratories Inc. (sekarang AT\&T Bell Laboratories). Beberapa alasan mengapa Bahasa $\mathrm{C}$ banyak digunakan, diantaranya adalah sebagai berikut :

1. Bahasa $\mathrm{C}$ hampir tersedia di semua jenis komputer

2. Bahasa $\mathrm{C}$ adalah bahasa yang terstruktur

3. Memiliki dukungan pustaka yang banyak

4. Proses eksekusi program lebih cepat

5. Kode Bahasa $\mathrm{C}$ sifatnya adalah portable dan fleksibel untuk semua jenis komputer.

6. Bahasa $\mathrm{C}$ hanya menyediakan sedikit katakata kunci, hanya terdapat 32 kata kunci.

\subsubsection{Perangkat Lunak Mikrokontroler ATMega32}

Sebuah mikrokontroler tidak akan bekerja bila tidak diberikan program untuk diisikan ke dalam mikrokontroler tersebut. Oleh karena itu, pada penelitian ini akan digunakan perangkat lunak CodeVisionAVR sebagai media penghubung antara program yang akan diisikan ke mikrokontroler ATMega32 yang menggunakan bahasa $\mathrm{C}$. Pemrograman mikrokontroler AVR dapat menggunakan low level language (assembly) dan high level language (C, Basic, Pascal, JAVA, dll) tergantung compiler yang digunakan. Bahasa Assembler pada mikrokontroler AVR memiliki kesamaan instruksi, sehingga jika telah menguasai pemrograman satu jenis mikrokontroler AVR, maka akan dengan mudah untuk memprogram mikrokontroler AVR jenis lain, tetapi bahasa assembler relatif lebih sulit dipelajari daripada bahasa $\mathrm{C}$, untuk pembuatan suatu proyek yang besar akan memakan waktu yang lama, serta penulisan programnya akan panjang.

Bahasa $\mathrm{C}$ memiliki keunggulan dibandingkan bahasa assembly yaitu penyusunan program akan lebih sederhana dan mudah pada proyek yang lebih besar. Bahasa $\mathrm{C}$ hampir bisa melakukan semua operasi yang dapat dikerjakan oleh bahasa mesin.

\subsection{LCD ( Liquid Crystal Display}

LCD ( Liquid Crystal Display) dapat berfungsi untuk menampilkan suatu nilai hasil sensor, Menampilkan teks atau menampilkan menu pada aplikasi mikrokontroler. M1632 merupakan modul LCD matrik dengan konfigurasi 16 karakter dan 2 baris dengan setiap karakter dibentuk oleh baris pixel dan kolom pixel ( 1 baris pixel terakhir adalah kursor )

\subsection{Buzzer}

Buzzer adalah sebuah komponen elektronika yang berfungsi untuk mengubahgetaran listrik menjadi getaran suara. Pada dasarnya prinsip kerja buzzer hampirsama dengan loud speaker, jadi buzzer juga terdiri dari kumparan yang terpasang pada diafragma. 


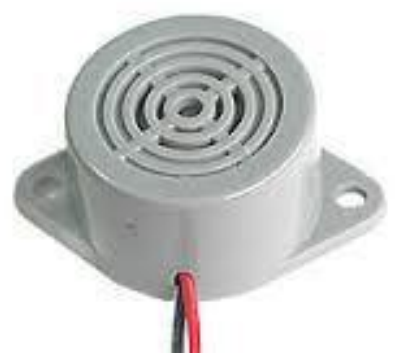

Gambar 2.9. Bentuk Buzzer

\subsection{Aktuator}

Aktuator merupakan peralatan mekanis untuk menggerakkan atau mengontrol suatu mekanisme atau sistem. Alat ini memiliki keluaran berupa vibrasi. Feedback pada pengguna diberikan dalam bentuk vibrasi agar hanya pengguna yang dapat merasakan feedback dari alat ini. Karena feedback yang berupa vibrasi, maka aktuator yang digunakan pada alat ini berupa motor vibrator. motor vibrator yang digunakan adalah sebagai berikut:
a. Diameter badan : $4 \mathrm{~mm}$
b. Panjang badan : $3 \mathrm{~mm}$
c. Rating tegangan : 3,7 Volt
d. Rating Kecepatan : $12500 \mathrm{rpm}$
e. Konsumsi daya :240 mW

\subsection{Second-Level Heading}

Heading pada level kedua dituliskan dengan boldface dengan menggunakan huruf besar dan huruf kecil. Heading dituliskan rata kiri.

Pada setiap gambar harus diberikan keterangan di bawah gambar. Keterangan pada tabel diberikan di atas tabel. Keterangan dituliskan dengan huruf kecil kecuali pada karakter pertama pada tiap kalimat. Seluruh gambar harus diberi penomoran secara berurutan. Jika Gambar besar maka diletakkan di tengah halaman (center alignment) dengan judul ditengah dan jika gambar kecil maka letakkan di tengah (center columns) baik itu pada kolom 1 ataupun pada kolom 2 dengan nama gambar rata justify, demikian halnya dengan tabel diawali di 3. METODE PENELITIAN

\subsection{Tempat dan Waktu Penelitian}

Penelitian ini dilakukan di Laboratorium Instrumentasi Medis Teknobiomedik, Laboratorim Robotik, Lab Elektrronika Departemen Fisika Fakultas Sains dan Teknologi Universitas Airlangga, mulai Oktober 2015 sampai dengan Januari 2016.

\subsection{Alat dan Bahan}

3.2.1 Alat yang digunakan dalam penelitian alat:
a. Sensor Ultrasonic 5 buah
b. Microcontroller ATMEGA32
c. USB PowerBank 5V
d. Buzzer
e. Motor DC
f. Tas
g. Eyeglass frame
h. Knee Protector

\subsubsection{Bahan yang digunakan dalam penelitian ini adalah:}

a. Datasheet komponen mekanisme desain ETA

b. Compiler Codevision AVR

c. Kazama AVR Downloader

d. Mouse USB

e. Kabel

f. $\mathrm{PC}$

g. Bahasa Pemograman $\mathrm{C}++$

h. PCB dan program PCB Maker

i. Printer

ii. Kabel tunggal

j. Solder dan Timah

\subsection{Prosedur Penelitian}

Pada penelitian dan pembutan ETA ini akan terbagi dalam lima tahapan untuk mencapai tujuan akhir. Lima tahapan tersebut adalah persiapan, perancangan, pembuatan, pengujian dan analisis data. Gambar 3.1 menunjukkan diagram alir prosedur penelitian secara lengkap serta penjelasannya pada subbab 


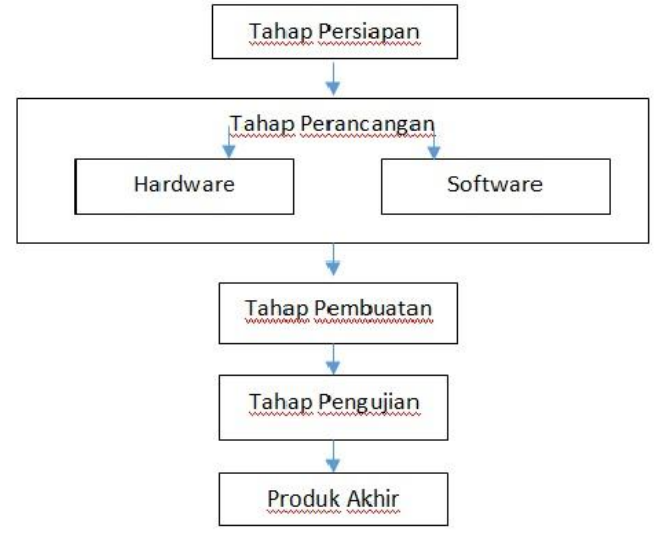

Gambar 3.1 alur tahapan pembuatan alat

\subsubsection{Tahap persiapan}

Pada tahap ini, proses yang dilakukan adalah pencarian referensi dan studi pustaka dari jurnal ilmiah, buku maupun tugas akhir yang berhubungan dengan ETA serta mengumpulkan alat dan bahan yang diperlukan dalam pembuatan alat.

\subsubsection{Tahap Perancangan}

Dalam tahap perancangan ini terbagi dalam 2 macam yaitu hardware dan software.

a. Tahap Perancangan

Hardware.

Hardware yang akan digunakan pada penelitian ini berupa sensor ultrasonic HC SR04, Mikrokontroller ATMEGA 32, LCD, buzzer, Motor DC. Ultrasonik berfungsi sebagai sensor yang akan mengambil jarak sebagai masukan. Mikrokontroller akan bertugas mengolah informasi yang diterima dari ultrasonic dengan software yang ditanamkan. Buzzer dan Motor DC akan berfungsi sebagai output, dimana jika semakin dekat halangan maka buzzer atau Motor DC akan berbunyi atau bergetar dengan tempo yang tertentu.

b. Tahap perancangan software.

Pembuatan Software pada mikrokontroler ATMEGA32 dalam penelitian ini menggunakan bahasa $\mathrm{C}$ yang dibuat menggunakan codevision AVR. Setelah itu dilakukan compiler agar siap dijalankan oleh hardware.

\subsubsection{Tahap Pembuatan}

Pada tahap pembutan, hardware akan dibuat per blok sesuai diagram. Setelah diuji bahwa semua telah sesuai dengan diagram akan ditanamkan software yang dibuat sesuai flowchart pada mikrokontroller.

\subsubsection{Tahap Pengujian dan Analisis}

Tahap pengujian diakukan dalam ruangan dan bertujuan untuk melihat hasil kinerja dari basis rule yang telah dibentuk. Tahap ini akan dilakukan percobaan dengan beberapa tahap,yaitu :

a. Pengujian masing-masing komponen. Dimana dalam pembuatan allat harus dipastikan komponen tidak rusak dan dapat digunakan dengan baik.

b. Pengujian program ketepatan jarak. Dimana respon time alat akan dibandingkan dengan perubahan jarak penghalang. Hasil pengujian ditampilkan pada LCD 16x2 dengan satuan $\mathrm{cm}$. Parameter : masing-masing sensor dapat dibaca oleh mikrokontroler dengan baik dan mengeluarkan output jarak pada LCD sesuai jarak benda sebenarnya.

c. Pengujian respon output sensor terhadap benda penghalang. Dimana akan diuji output dari hasil pengukuran benda penghalang yang dapat tedeteksi oleh alat. Parameter : pada pengukuran jarak tertentu maka output akan aktif.

\section{HASIL DAN PEMBAHASAN}

\subsection{Uji Coba Alat}

Setelah pembuatan Prototipe Multi Ultrasonic Electronic Travel Aids (MU-ETA) Sebagai Alat Bantu Penunjuk Jalan Bagi Tuna Netra selesai, tahap berikutnya adalah proses pengujian dan pembahasan tentang kinerja dari alat ini. Pengujian ini dilakukan untuk 
mengetahui cara kerja dan fungsi dari masingmasing komponen utama serta mengetahui cara pengoperasian dari alat ini.

\subsubsection{Pengujian Tegangan Catu Daya USB PowerBank 5V}

Pengujian rangkaian catu daya dilakukan dengan tahapan sebagai berikut :

1. Panel penunjuk multimeter diarahkan pada Volt DC.

2. Multimeter diatur nilainya sesuai dengan tegangan yang akan diukur.

3. Kabel merah pada multimeter dihubungkan dengan kutub positif input VCC dan kabel hitam dihubungkan dengan kutub negatif input Ground.

4. Jika jarum pada multimeter menunjukkan nilai yang tepat maka trafo dalam keadaan baik.

Pada rangkaian ini Tegangan yang dibutuhkan adalah sebesar 5 Volt. Besaran tegangan yang dihasilkan merupakan tegangan DC.

\subsubsection{Pengujian Rangkaian Mikrokontroler}

Pengujian rangkaian mikrokontroler dilakukan dengan langkah sebagai berikut :

1. Dibuat rangkaian LED dengan anoda ke PORTA.0 tanpa ditambah dengan resistor pull up

2. IC ATMEGA 32 diberi tegangan $+5 \mathrm{~V}$

3. kaki Positif LED dihubungkan dengan PORTA.0

4. Kaki negatif LED dihubungkan dengan Ground

4. Dibuat program dengan bahasa $C$. Listing programnya sebagai berikut : PORTA=0b10000000; // Set PORTA delay_ms(1000); //

delay 1 detik delay_ms(1000); PORTA=0b00000000; // set PORTA

Delay 1 detik delay_ms(1000); // delay_ms(1000);

5. Jika LED menyala maka IC ATMEGA 32 dalam keadaan baik.
Sistem kerja dari mikrokontroler ATMEGA 32 antara lain :

1. Melakukan proses rutin inisialisasi, yakni proses untuk mengkondisikan informasi yang dibutuhkan sebelum proses pengambilan data jarak dilakukan sensor ultrasonik. Adapun inisialisasi ini dilakukan terhadap display LCD.

2. Melakukan proses rutin interupsi, yakni proses pengambilan data jarak dilakukan. Urutan proses kerjanya adalah :

a. Memerintahkan sensor ultrasonik untuk melakukan pengukuran jarak.

b. Mengambil data jarak dari sensor ultrasonik.

3. Melakukan proses pengolahan data yakni dengan cara :

a. Menyimpan data dan mengolah data jarak.

b. Konversi data HEX ke ASCII (display).

\subsubsection{Pengujian Rangkaian LCD}

Tujuan pengujian rangkaian LCD adalah untuk mengecek apakah LCD bekerja dengan baik. Untuk mengetahui apakah LCD berfungsi dengan baik atau tidak, bisa dilakukan dengan menghubungkannya dengan catu daya yang diberi tegangan 5 Volt.

Pin - pin pada LCD yang dihubungkan antara lain pin VSS dihubungkan dengan ground pada catu daya dan VDD dihubungkan dengan kutub positif $+5 \mathrm{v}$ pada catu daya. Untuk mengatur tingkat kecerahan atau kontras dari LCD dilakukan dengan cara menghubungkan pin VEE dengan trimpot. Setelah rangkaian tersebut dihubungan dengan arus listrik, LCD dapat menyala dengan baik dan layak digunakan.

\subsubsection{Pengujian Rangkaian Sensor Ultrasonik HC-SR04}

Pengujian sensor ultrasonik bertujuan untuk mengetahui jarak minimum dan maksimum yang dapat diukur oleh sensor ultrasonik HC-SR04 serta membandingkan jarak sebenarnya dengan jarak hasil pengukuran menggunakan sensor ultrasonik HC-SR04. 
Pengujian rangkaian sensor ultrasonik SRF04 dilakukan dengan menghubungkan antara modul sensor ultraonik SRF04 dengan rangkaian mikrokontroler ATMEGA 32. Pin pin pada SRF04 yang dihubungkan antara lain pin sumber tegangan $+5 \mathrm{v}$ dihubungkan dengan kutub VCC $+5 \mathrm{v}$, Pin Trigger dihubungkan dengan PORTD.0, Pin Echo dihubugkan dengan PORTD.1 dan pin Ground dihubungkan dengan Ground. Cara kerja dari sensor ultrasonik SRF04 adalah mula - mula SRF04 diaktifkan melalui pin Trigger minimal $10 \mu$ s dengan mengirimkan pulsa positif dari IC mikrokontroler. Selanjutnya pin TX akan mengirim sinyal pada saat logika 1 atau high yang mengenai penghalang dan sinyal pantulan dari penghalang akan diterima oleh RX. Pada saat menerima sinyal pantulan, RX berlogika 0 atau low, dimana sinyal dari RX akan dilewatkan melalui pin Echo. Lebar sinyal dari Echo inilah yang akan digunakan untuk pengukuran jarak. Selanjutnya adalah melakukan ujicoba pegukuran jarak sensor ultrasonik SRF04 dengan cara menempatkan sensor ultrasonik di depan penghalang dan memvariasi jarak pengukuran.

Perintah dalam software adalah sebagai berikut

void ultrasonic1(void)

// Buka perintah panggilan ultasonik

\{

jarak $=0$;

//inisial jarak

PORTD.0 $=1$;

// open trigger

DDRD.0=1;

// open trigger

delay_us(10);

// delay minimum triger

PORTD. $0=0$;

// tutup triger

DDRD.0=0;

delay_us(10);

jarak $=0$;

while(PIND.1==0) $\{;\} ; \quad$ // jika

sinyal low maka diam

while(PIND.1==1)

// jika sinyal masuk maka jarak ++ $\underset{\}}{\text { jarak++; }}$

Hasil yang didapat dari pengukuran jarak adalah sebagai berikut :

Dari pengujian yang dilakukan 10 kali untuk masing-masing sensor, maka didapatkan nilai rata-rata pembacaan jarak (mean) sehingga dapat dihitung nilai standart deviasi dan error rate-nya.

Untuk mendapatkan nilai error rate menggunakan rumus :

\section{Eror \% = (Jarak yang diukur - Jarak sebenarnya) $\mathrm{x} 100$ Jarak yang diukur}

Setelah didapatkan nilai-nilai tersebut, dilakukan uji tes Pair T-Tailed test hingga didapatkan keputusan dapat diterima.

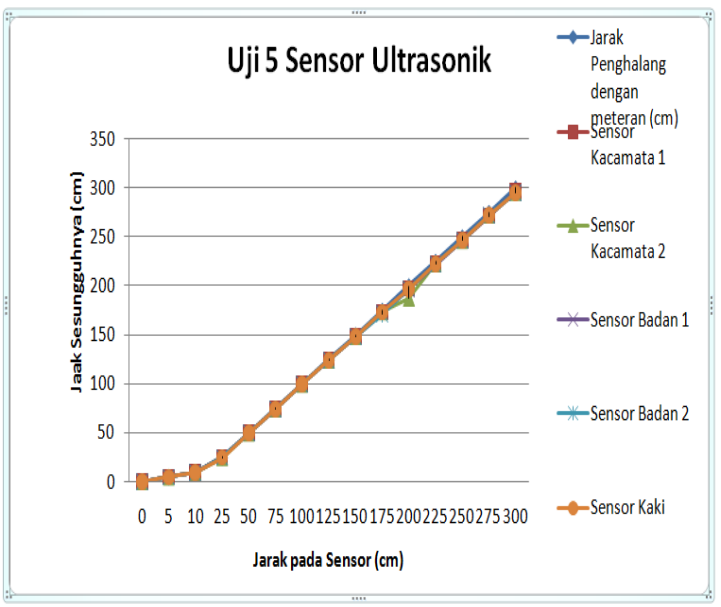

Gambar 4.8 Line diagram uji sensor ultrasonic

Dari hasil uji paired T-Test didapatkan keputusan bahwa ke 5 sensor ultrasonic mampu mengukur jarak mulai dari $0 \mathrm{~cm}$ sampai dengan $300 \mathrm{~cm}$ dengan error rate kurang dari 3 persen dan dapat diterima sebagai pengganti penggaris dalam mengukur jarak. Angka yang ditampilkan pada LCD terdapat selisih dengan jarak sebenarnya, hal ini dipengaruhi oleh beberapa faktor yang dapat mengurangi keakuratan pengukuran jarak dengan menggunakan sensor ultrasonik HC-SR04 diantaranya adalah karakteristik penghalang atau objek yang dapat memantulkan sinyal kembali ke sensor 
ultrasonik. Secara uji coba, sensor ultrasonic HC-SR04 ini dapat bekerja dengan baik sesuai dengan spesifikasi dari sensor ultrasonik HCSR04 yaitu dapat mengukur jarak mulai dari jarak minimum $3 \mathrm{~cm}$ sampai dengan jarak maksimum $3 \mathrm{~m}$.

\subsubsection{Pengujian Rangkaian Buzzer.}

Pengujian rangkaian speaker dimaksudkan untuk mengecek apakah speaker bekerja dengan baik.

Pengujian Buzzer dapat dilakukan dengan menghubungkan kutub posisitf pada VCC $5 \mathrm{~V}$ dan kutub negatif pada Ground. Setelah dicek buzzer masih mengeluarkan bunyi. Sehingga buzzer dalam keadaan baik.

\subsubsection{Pengujian Motor DC}

Tujuan pengujian rangkaian Motor DC adalah untuk mengecek apakah Motor DC bekerja dengan baik. Untuk mengetahui apakah Motor DC berfungsi dengan baik atau tidak, bisa dilakukan dengan menghubungkan kutub posisitf pada VCC $5 \mathrm{~V}$ dan kutub negatif pada Ground. Setelah dicek motor DC masih beputar. Sehingga motor $D C$ dalam keadaan baik.

\subsection{Pengujian Bahasa Pemrogaman Alat}

Untuk pengujian program, penulis akan menganalisa program yang telah dibuat menggnakan progam CodeVision AVR 2 dan disesuaikan dengan hasil output dari masingmasing rangkaian. Selain itu akan ditampilkan hasil compile program dijalankan pada software Kazama yang berekstension HEX yang berfungsi sebagai downloader ke IC ATMEGA32.

\subsubsection{Bahasa Pemrograman CodeVision AVR2 (CV AVR2)}

Pengujian pemrograman dilakukan setelah semua komponen elektronika dan komponen mikrokontroler terpasang dengan benar. Pemrograman dilakukan dengan menggunakan bahasa $C$ yaitu dengan Codevision AVR2 (CV AVR2). Listing program ditulis dengan menggunakan program Notepad di dalam program CV AVR2 dan file disimpan dengan ekstensi ".C". Kemudian file ".C" tersebut di- compile untuk dirubah menjadi file ".hex". Langkah-langkah pemrogaman CV AVR2 adalah sebagai berikut :

Program ditulis dengan menggunakan CV AVR2 kemudian file disimpan dengan nama LCDUltrasonik.C

\subsubsection{Pemrograman Kazama AVR Downloader}

Pengujian pemrograman downloader ini dilakukan setelah proses compile pada pemrograman CodeVision AVR2 berhasil dilakukan. File bernama LCDUltrasonik.HEX akan di download ke chip IC ATMEGA32 menggunakan program kazama AVR Downloader. Hasil Pengujian downloader menggunakan progam Kazama AVR Downloader behasil dilakukan.

\subsection{Pengujian Alat Keseluruhan}

Pengujian rangkaian keseluruhan dilakukan setelah pengecekan mulai dari bagian masing-masing rangkaian penyusun dan pengisian program ke dalam IC mikrokontroler ATMEGA32 selesai. Adapun langkah-langkah pengujiannya adalah sebagai berikut :

1. Menghubungkan kabel dari rangkaian ke USB Catu daya $5 \mathrm{~V}$.

2. Mengatur jarak penghalang yang digunakan untuk pengukuran.

3. Mencatat hasil pengukuran untuk kemudian dianalisa.

Tabel 4.9 Hasil pengujian respon kacamata 
Jurnal Biosains Pascasarjana Vol. 18 (2016) pp

(C) (2016) Sekolah Pascasarjana Universitas Airlangga, Indonesia

\begin{tabular}{|r|r|r|l|}
\hline $\begin{array}{l}\text { Jarak } \\
\text { Penghalang } \\
\text { dengan } \\
\text { meteran }(\mathbf{c m})\end{array}$ & $\begin{array}{l}\text { Jarak Penghalang } \\
\text { dengan Sensor } \\
\text { kacamata 1 }\end{array}$ & $\begin{array}{l}\text { Jarak Penghalang } \\
\text { dengan Sensor } \\
\text { kacamata 2 }\end{array}$ & $\begin{array}{l}\text { Buzzer } \\
\text { Kacamata }\end{array}$ \\
\hline 0 & $\sim$ & $\sim$ & mati \\
\hline 10 & 10.1 & 10.1 & menyala terus \\
\hline 25 & 25.1 & 25 & menyala terus \\
\hline 50 & 49.7 & 49.8 & menyala terus \\
\hline 75 & 74.6 & 73.9 & Menyala 1x \\
\hline 100 & 101 & 100 & Menyala 1x \\
\hline 125 & 124.7 & 124.5 & Menyala 1x \\
\hline 150 & 149 & 149.5 & Tidak menyala \\
\hline 175 & 174.3 & 174.5 & Tidak menyala \\
\hline 200 & 198.3 & 199.1 & Tidak menyala \\
\hline 250 & 246.4 & 245.2 & Tidak menyala \\
\hline 300 & 294 & 293.2 & Tidak menyala \\
\hline
\end{tabular}

Tabel 4.10 Hasil pengujian respon badan

\begin{tabular}{|r|r|r|l|}
\hline $\begin{array}{l}\text { Jarak } \\
\text { Penghalang } \\
\text { dengan } \\
\text { meteran }(\mathrm{cm})\end{array}$ & $\begin{array}{l}\text { Jarak Penghalang } \\
\text { dengan Sensor } \\
\text { Badan 1 }\end{array}$ & $\begin{array}{l}\text { Jarak Penghalang } \\
\text { dengan Sensor } \\
\text { Badan 2 }\end{array}$ & \\
\hline 0 & $\sim$ & $\sim$ & Buzzer Badan \\
\hline 10 & 10.1 & 10.1 & menyala terus \\
\hline 25 & 24.5 & 25 & menyala terus \\
\hline 50 & 49.7 & 50.2 & menyala terus \\
\hline 75 & 74.2 & 73.5 & Menyala 1x \\
\hline 100 & 102.2 & 98.1 & Menyala 1x \\
\hline 125 & 122.2 & 124 & Menyala 1x \\
\hline 150 & 146 & 148 & Tidak menyala \\
\hline 175 & 172 & 174 & Tidak menyala \\
\hline 200 & 194 & 197 & Tidak menyala \\
\hline 250 & 242 & 246 & Tidak menyala \\
\hline 300 & 294 & 294 & Tidak menyala \\
\hline & & & \\
\hline & & & \\
\hline & & & \\
\hline
\end{tabular}

Tabel 4.11 Hasil pengujian respon kaki

\begin{tabular}{|r|r|l|l|l|}
\hline $\begin{array}{l}\text { larak } \\
\text { Penghalang } \\
\text { dengan } \\
\text { meteran }(\mathrm{cm})\end{array}$ & $\begin{array}{l}\text { Jarak Penghalang } \\
\text { dengan Sensor } \\
\text { Kaki1 }\end{array}$ & & & \\
\hline & Buzzer kacamata & Buzzer Badan & Motor DC \\
\hline 10 & 10.1 & Tidak Aktif & Tidak Aktif & menyala terus \\
\hline 25 & 24.5 & Tidak Aktif & Tidak Aktif & menyala terus \\
\hline 50 & 49.7 & Tidak Aktif & Tidak Aktif & menyala terus \\
\hline 75 & 74.2 & Tidak Aktif & Tidak Aktif & Menyala 1x \\
\hline 100 & 102.2 & Tidak Aktif & Tidak Aktif & Menyala 1x \\
\hline 125 & 122.2 & Tidak Aktif & Tidak Aktif & Menyala 1x \\
\hline 150 & 146 & Tidak Aktif & Tidak Aktif & Tidakmenyala \\
\hline 175 & 172 & Tidak Aktif & Tidak Aktif & Tidak menyala \\
\hline 200 & 194 & Tidak Aktif & Tidak Aktif & Tidak menyala \\
\hline 250 & 242 & Tidak Aktif & Tidak Aktif & Tidak menyala \\
\hline 300 & 294 & Tidak Aktif & Tidak Aktif & Tidak menyala \\
\hline
\end{tabular}

Sensor ultrasonik bekerja berdasarkan prinsip pantulan gelombang suara, dimana sensor menghasilkan gelombang suara yang kemudian menangkapnya kembali dengan perbedaan waktu sebagai dasar penginderaannya. Perbedaan waktu antara gelombang suara yang dipancarkan dan yang diterima kembali adalah berbanding lurus dengan jarak atau tinggi objek yang memantulkannya. Pengujian alat dilakukan dengan mengatur jarak penghalang yang ada di depan sensor.

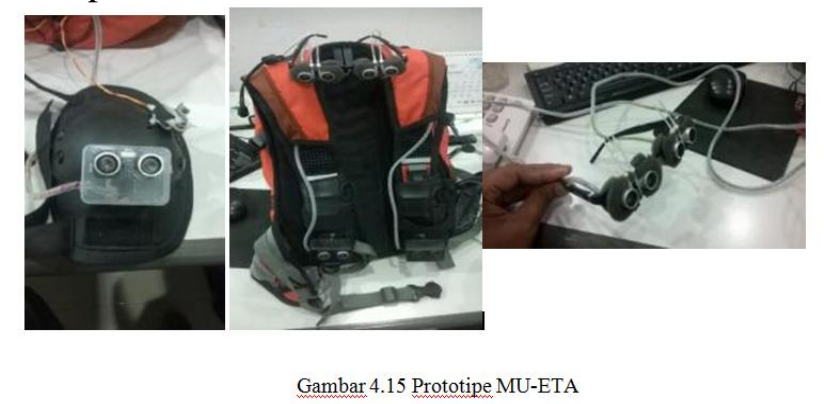

Dari pengujian alat yang dilakukan didapatkan hasil pengukuran yang mempunyai selisih dengan jarak sebenarnya. Karakteristik objek penghalang berpengaruh pada hasil pengukuran jarak dengan menggunakan sensor ultrasonic HC SRF04. Range jarak yang digunakan untuk membedakan karakter bunyi dari speaker yaitu $0 \mathrm{~cm}-3 \mathrm{~cm}$ (mati), $3 \mathrm{~cm}-$ $50 \mathrm{~cm}$ (Selalu menyala) dan $50 \mathrm{~cm}-130 \mathrm{~cm}$ (menyala $1 \mathrm{x}$ berulang). Bunyi speaker yang berbeda - beda setiap rangenya menjadi alarm agar mudah dikenali oleh pengguna. Hasil pengujian dapat membuktikan bahwa sensor ultrasonik bekerja berdasarkan kemampuan penghalang memantulkan kembali gelombang ultrasonik yang dikirim oleh sensor ultrasonik, gangguan pada pendeteksiaan sensor ultrasonik dapat diakibatkan oleh karakteristik penghalang yang kurang mampu untuk memantulkan gelombang bunyi dengan baik dan adanya interferensi gelombang dengan frekuensi yang sama. Namun ETA yang di buat pada penelitian ini belum mampu mendeteksi halangan berupa lubang dan anak tangga menurun. Hal ini disebabkan karena sudut pantul gelombang ultrasonik untuk halangan tersebut yang belum terbaca oleh sensor ultrasonic bagian kaki. 


\section{KESIMPULAN DAN SARAN}

\subsection{Kesimpulan :}

Dari keseluruhan proses penelitian ini, dapat disimpulkan sebagai berikut :

1. Berdasarkan hasil penelitian, desain Multi Ultrasonic Electronic Travel Aids (MUETA) ang telah dirancang dapat digunakan sebagai alat bantu bagi penderita tuna netra dengan variable utama yaitu jarak alat terhadap halangan dengan rerata kinerja masing-masing sensor ultrasonik $\pm 98 \%$ dengan kalibrasi utama berupa meteran.

2. MU-ETA dapat mengenali halangan ketika dilakukan uji coba melewati halangan pada 3 bagian tubuh yaitu kepala, badan dan kaki baik secara bersamaan maupun secara per bagian.

\subsection{Saran :}

Dari hasil penelitian dalam pembuatan MU-ETA berbasis Mikrokontroler ATMEGA 32 ini, maka penulis memberikan saran kepada pembaca dalam rangka kemajuan alat ini ke depan, diantaranya :

1. Pengembangan model Prototipe MU-ETA Berbasis Mikrokontroler ATMEGA 32. Dimana alat yang dibuat tidak hanya dalam bentuk prototipe, tetapi langsung diterapkan dalam lapangan.

2. Penambahan sensor kaki untuk dapat digunakan sebagai sensor menuruni anak tangga

3. Penggunaan Bluetooth atau Radio Frekuensi sebagai pengganti kabe' ${ }_{54}$ '। sensor Ultrasonik.

4. Penggunaan saklar untuk mempermudah saat menghidupkan dan mematikan alat.

\section{UCAPAN TERIMA KASIH}

Puji Syukur Alhamdulillah yang sebesarbesarnya peneliti panjatkan kepada ALLAH SWT yang telah mewujudkan impian serta memberikan segala jalan kemudahan, kesehatan dan akal pikiran dalam menyelesaikan tesis yang berjudul "Multi Ultrasonic Electrinic Travel Aids (MU-ETA) Sebagai Alat Bantu Penunjuk Jalan Bagi Tuna Netra" ini. Tidak lupa sholawat dan salam kepada nabi besar Muhammad SAW peneliti selalu ucapkan dalam setiap langkah menuntut ilmu.

Selama peneliti menulis tesis ini, peneliti menyadari begitu banyak bantuan dari orangorang yang telah berjasa bagi peneliti, baik secara moril maupun materiil. Pada kesempatan ini, peneliti ingin menyampaikan terima kasih serta penghargaan setinggitingginya kepada orang-orang berjasa sebagai berikut :

1. Rektor Universitas Airlangga, Prof. Dr.MOH Nasih, SE,MT.,Ak.,CMA, atas pemberian kesempatan belajar dalam menggali ilmu di Universitas Airlangga guna menjadi manusia yang bermanfaat bagi masyarakat, bangsa dan Negara.

2. Direktur Pasca Sarjana, Prof. Dr. Sri Iswati, SE.,M.Si.,Ak., atas pemberian kesempatan belajar dalam menggali ilmu di sekolah Pascasarjana guna menjadi manusia yang professional dalam bidang pengembangan sumber daya manusia.

3. Kaprodi studi S2 Teknobiomedik, Dr. Suryani Dyah Astuti, M.Si atas masukan dan saran selama melakukan penelitian tesis ini berjalan.

4. Dosen Pembimbing ketua Prof.Dr.Retna Apsari,M.Si. yang dengan sabar luar biasa membimbing peneliti dalam penelitian tesis ini serta tak henti-hentinya memberi dorongan semangat dan kepercayaan diri kepada peneliti untuk terus berkarya dan menyelesaikan tesis ini secepatnya.

5. Dosen Pembimbing II Prof.Dr.Ir.Suhariningsih, yang juga dengan sabar memberikan bimbingan kepada peneliti dan dukungan moral yang sangat peneliti butuhkan selama penelitian berlangsung.

6. Kedua Orang Tua peneliti, Ayahanda Mochammad Talkah dan Ibunda Liesa Sulistyorini tercinta, Ayah mertua Anwar (E DOK) dan Ibunda Mertua Dahlia Anwar yang dengan do'a dan restunya selalu menyertai perjalanan penelitian ini. 
7. Istri peneliti Mutia Rizky Asriani tercinta dan ananda Maira Nada Aishalova tersayang yang selalu setia menemani dan memberi kasih sayang serta dukungan semangat dalam mengerjakan penelitian tesis ini.

8. Bapak Prima Zulio Rosa, Eks Kepala Cabang PT.Bank Syariah Mandiri KC Sidoarjo yang paling saya hormati karena kepercayaan yang telah diberikan selama peneliti bekerja di dalam tim-nya dan atas persetujuan beliau-lah peneliti dapat melanjutkan perkuliahan sambil menjalankan kewajiban bekerja secara bersamaan.

9. Kakak-kakak tercinta Mas Titis, Mas Agus, Mas Ayi, Mas Dayat,Mbak Dewi, Devi, Mbak Fit, dan keluarga besar yang tidak tersebutkan, terima kasih atas dukungan dan doanya hingga terselesaikan penelitian tesis ini.

10. Keluarga PT.Bank Syariah Mandiri Surabaya pada Umumnya, dan Cabang Sidoarjo dan Surabaya Jembatan Merah pada khususnya. Terima kasih atas semangat, tawa dan doa yang selalu diberikan setiap langkah menjalani ikhtiar dan menyelesaikan tesis ini.

11. Semua orang-orang yang secara langsung maupun tidak langsung ikut membantu terselesaikannya penelitian tesis ini, terima kasih yang sebesar-besarnya atas dukungan dan doanya.

\section{DAFTAR PUSTAKA}

Andrianto Heri, 2013, Pemrograman mikrokontroler AVR ATmega16 menggunakan bahasa $\mathrm{C}($ Codevision AVR) edisi revisi, Bandung, Penerbit Informatika

Ajay Mitthal, Sanjeef Sofat, 2010, A survey of Electronic Travel Aids: sensor perspective, PEC University Of Technology, India

Atmel Corporation, 2003,8 bit AVR Microcontroller with 32Kbyte In-System Programmable Flash datasheet, USA
Badan Kementrian dan Pengembangan Kesehatan Kementrian Kesehatan RI, Desember 2013. Riset Kesehatan Dasar 2013, Jakarta.

Dambhre,Shruti, 2011, Smart stick for blind : Obstacle Detection, Artificial vision and Real-time assistance via GPS, journal for $2^{\text {nd }}$ national conference on information and communication Technology (NCICT).

Ercoli, Marchioni, Scalise, 2013,A weareable multipoint Ultrasonic Travel Aids for Visually Impared, IMEKO,conf series 459.

Infodatin, 2014, Situasi Gangguan Penglihatan dan Kebutaan, Jakarta

Jameco Electronic, 2008, Ping))) parallax ultrasonic distance sensor, Parallax Inc, USA

Muhammad Nur Meizani, Abdul Muid, Tedy Rismawan, 2015, Pembuatan Prototipe Kaca Mata Elektronik Untuk Tuna Netra Berrbasis Mikrokontroler Menggunakan Sensor Ultrasonik, Jurnal Coding Volume 03 no 2 hal 88-99, 2015.

Sankaar, Abarna, Lavanya, Lakshmi, 2013,Embedded Glove' to Aid the Visually Impaired, IJEEDC, Vol 1 Issue 1 March.

Shripat S. Bhatlawande, 2012,Ultrasonic Spectacles and Waist-Belt for visually impaired and blind person, IEEE, vol 12, March.

Subandi, 2009. Alat bantu Mobilitas Untuk Tuna Netra Berbasis Elektronik, Journal Teknologi Vol. 2 Nomor 1, Yogyakarta AKPRIND. 